\title{
High Temperature SAW wireless sensors based on YCOB and Langasite
}

\author{
Bin Peng ${ }^{1, *}$, Yilin Cui ${ }^{1, a}$, Lin Shu ${ }^{1, b}$, Yihong Zeng ${ }^{1, c}$, Wanli Zhang ${ }^{1, d}$
}

${ }^{1}$ State Key Laboratory of Electronic Thin Films and Integrated Devices, University of Electronic Science and Technology of China, Chengdu, 610054, P. R. China

\author{
*bpeng@uestc.edu.cn, ’a3ingmtg@gmail.com, bs89s89s@126.com, cyihongz219@163.com,
}

Keywords: SAW wireless sensor, high temperature, langasite, yttrium calcium oxoborate

Abstract High temperature SAW resonators were fabricated on $\mathrm{YCa}_{4} \mathrm{O}\left(\mathrm{BO}_{3}\right)_{3}$ substrates with cutting type of $\mathrm{X}-90^{\circ}$ and Z-90 ${ }^{\circ}$ and langasite substrates with Euler angle of $\left(0^{\circ}, 138.5^{\circ}, 117^{\circ}\right)$ and $\left(0^{\circ}\right.$, $\left.138.5^{\circ}, 27^{\circ}\right)$. The temperature characteristics of these resonators have been studied in this paper. The results show that resonators on all four substrates have high temperature stability up to $600{ }^{\circ} \mathrm{C}$. The resonance frequency of the SAW resonators based on $\mathrm{YCa}_{4} \mathrm{O}\left(\mathrm{BO}_{3}\right)_{3}$ substrates decrease more linearly with temperature than those on langasite substrates. The temperature sensitivity of SAW resonator with Z- $90^{\circ} \mathrm{YCOB}$ substrates and $\mathrm{X}-90^{\circ} \mathrm{YCOB}$ substrates are $21.22 \mathrm{kHz} /{ }^{\circ} \mathrm{C}$ and $13.44 \mathrm{kHz} /{ }^{\circ} \mathrm{C}$, respectively. It suggests that $\mathrm{YCa} \mathrm{Ca}_{4} \mathrm{O}\left(\mathrm{BO}_{3}\right)_{3}$ with cutting type of $\mathrm{Z}-90^{\circ}$ is suitable candidate for piezoelectric substrate used for sensors working in high temperature environment.

\section{Introduction}

Because of their high performance, small size, and high reproducibility [1], SAW devices have been widely used in aerospace, energy and telecommunication industries. Also because of their high accuracy, SAW devices are suitable for sensor applications such as pressure sensors, biosensors, temperature sensors, and mass sensors [2]. There has been an increasing demand for sensors which can work wirelessly in harsh environment with high pressure, high temperature and aggressive chemical material. SAW materials like yttrium calcium oxoborate $\left(\mathrm{YCa}_{4} \mathrm{O}\left(\mathrm{BO}_{3}\right)_{3}, \mathrm{YCOB}\right)$ and Langasite $\left(\mathrm{La}_{3} \mathrm{Si}_{5} \mathrm{O}_{14}, \mathrm{LGS}\right)$ are capable to work in such environment due to their perfect chemical stability. Both materials have high piezoelectric coefficient, high electromechanical coupling coefficient and high melting points above $1400{ }^{\circ} \mathrm{C}$, making them suitable for work at high temperature. Kyungrim Kim and Shujun Zhang [3] designed and build high temperature vibration sensing applications using YCOB capable to work at temperature range from room temperature to $1000{ }^{\circ} \mathrm{C}$. Langasite had been studied for both high temperature bulk acoustic wave (BAW) and surface acoustic wave applications [4-6]. Thiele and Cunha [7] prepared LGS gas sensors used to detect $\mathrm{C}_{2} \mathrm{H}_{4}$ in $\mathrm{N}_{2}\left(\mathrm{C}_{2} \mathrm{H}_{4} / \mathrm{N}_{2}\right)$ which were capable to work up to $750{ }^{\circ} \mathrm{C}$. Wilson and Rogge [8] developed a system used for fastener failure detection with multiple LGS devices.

In this work, we fabricated SAW resonators on YOCB and LGS substrates. The characteristics of the prepared SAW sensors based on these two types piezoelectric crystal at high temperature were investigated.

\section{Experiment}

In this work, SAW resonators were deposited on LGS substrates with Euler angle of $\left(0^{\circ}, 138.5^{\circ}, 117^{\circ}\right)$ (device A) and $\left(0^{\circ}, 138.5^{\circ}, 27^{\circ}\right)$ (device $\left.\mathrm{B}\right)$ and $\mathrm{YCa}_{4} \mathrm{O}\left(\mathrm{BO}_{3}\right)_{3}$ substrates with cutting type of $\mathrm{X}-90^{\circ}$ (device C) and Z-90 (device D). The SAW resonators in this work had a typical structure of one port SAW resonator as shown in Fig. 1. It consisted of an interdigital transducer (IDT) and two reflector banks. The IDT deposited on LGS substrates contained 101 equal-interval-finger electrodes while the IDT deposited on YCOB substrates contained 100 equal-interval-finger electrodes. Both these IDTs had finger width of $3 \mu \mathrm{m}$ and yielded an acoustic wavelength of $12 \mu \mathrm{m}$. Reflector banks were fabricated on both sides of IDT. The reflector banks on LGS substrates contained 400 
short-circuited gratings while the reflector banks on YCOB substrates contained 500 short-circuited gratings. The aperture $\mathrm{W}$ was $1200 \mu \mathrm{m}$. All the electrodes were patterned by lift-off photolithography techniques. Au was chosen as the electrode material in this work. A 100-nm-thick Au film was deposited on substrates with a 10-nm-thick $\mathrm{Ti}$ adhesion layer beneath it. The prepared SAW resonators were annealed at $600{ }^{\circ} \mathrm{C}$ in pure $\mathrm{N}_{2}$ before measurement.

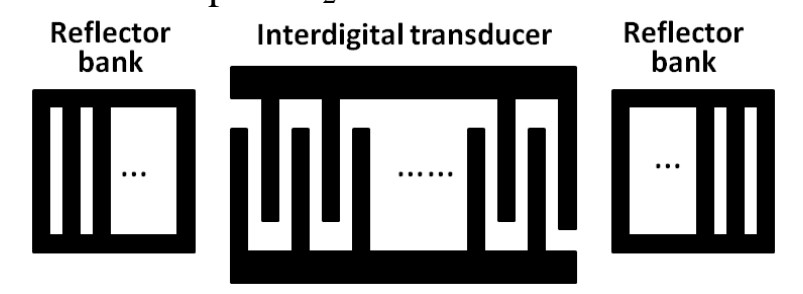

Fig. 1. Schematic illustration of the one-port surface acoustic wave (SAW) resonator.

The prepared SAW devices were measured wirelessly under different temperatures from room temperature to $600{ }^{\circ} \mathrm{C}$ to investigate their temperature-frequency characteristics. The SAW resonator was boned with a $\lambda / 4$ dipole antenna and placed in a furnace. Then the frequency characteristics of the SAW sensor were measured wirelessly by a vector network analyzer (Agilent, E5071C) through another $\lambda / 4$ interrogation dipole antenna. The measurement setup is shown in Fig. 2.

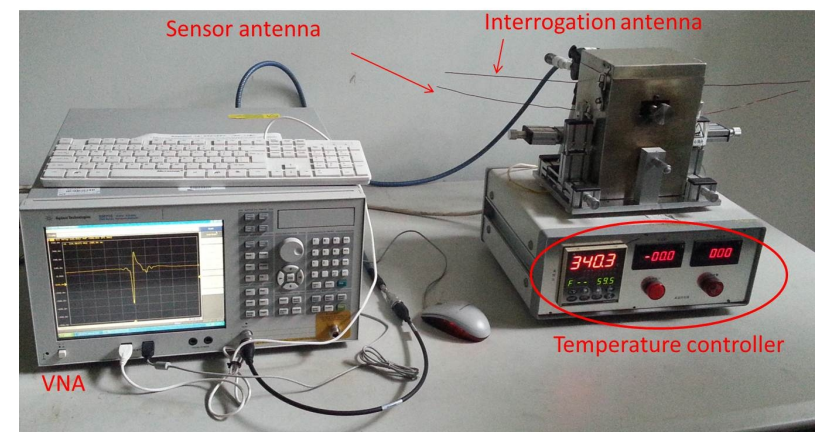

Fig. 2. Photo of the high temperature measurement setup.

\section{Results and discussion}

Fig. 3 shows the measured group delay curves of four different SAW devices under room temperature. From Fig. 3, it can be observed that the each group delay curve shows a sharp peak at resonance frequency. The resonance frequency of the device A, device B, device $\mathrm{C}$ and device $\mathrm{D}$ are 216.1185 $\mathrm{MHz}, 225.1375 \mathrm{MHz}, 230.53 \mathrm{MHz}$ and $278.94 \mathrm{MHz}$, respectively.

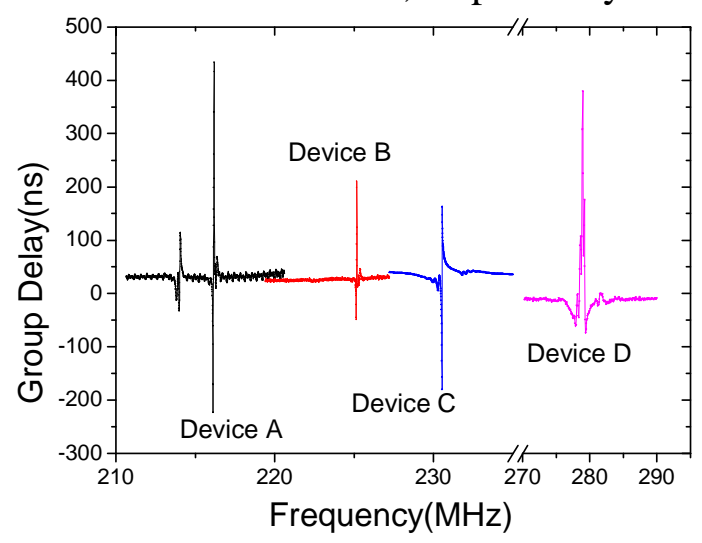

Fig. 3. Group delay curves of four SAW devices under the room temperature.

The resonance frequency for SAW resonator can be expressed as [9]:

$$
f_{r}=\mathrm{v} / \lambda
$$

where $v$ is the SAW velocity in the substrates and $\lambda$ is the wavelength. In this work, the wavelength is $12 \mu \mathrm{m}$. Then the SAW velocities of the device A, device B, device C and device D are $2593 \mathrm{~m} / \mathrm{s}, 2701$ 
$\mathrm{m} / \mathrm{s}, 2766 \mathrm{~m} / \mathrm{s}$ and $3347 \mathrm{~m} / \mathrm{s}$, respectively. We can find the SAW velocity of YCOB is higher than that of LGS. These results are very close to the reported data $[10,11]$.

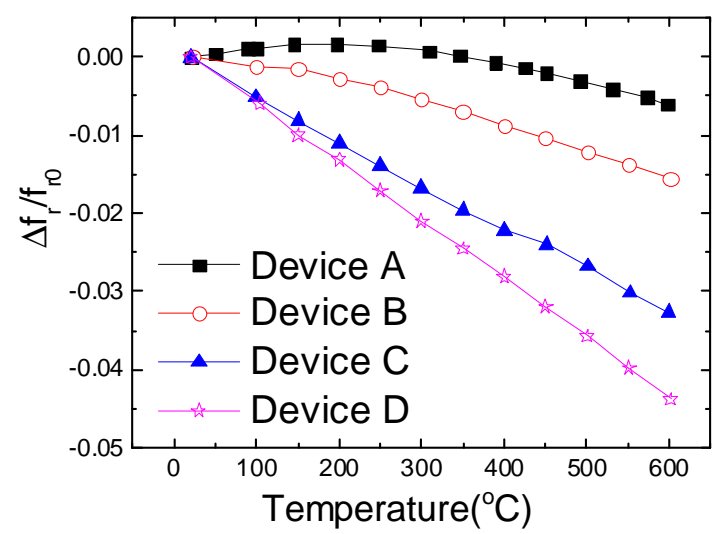

Fig. 4. Relative frequency shift in resonance frequency as a function of temperature.

Fig. 5 shows relative frequency shift in resonance frequency as a function of temperature from room temperature up to $600{ }^{\circ} \mathrm{C}$, where $\mathrm{f}_{\mathrm{r} 0}$ is the resonance frequency at room temperature. It can be found that the resonance frequency of the device A increases with increasing temperature below 200 ${ }^{\circ} \mathrm{C}$, and then it decreases with further increase of temperature. This result suggests that this SAW device cannot be used at temperature from room temperature to $600{ }^{\circ} \mathrm{C}$ because the $\mathrm{f}_{\mathrm{r}} \mathrm{vs}$. temperature curve is non-monotonic. On the other hand, the resonance frequencies of device $\mathrm{B}$, device $\mathrm{C}$ and device D decrease monotonically with the increase of temperature, which indicates that these three SAW device can be used as temperature sensor. The thermal effects on the resonance frequency of the SAW resonator are due to the change in the length of the substrate and the substrate material parameter including density and elastic coefficients [13].

The temperature coefficient of frequency (TCF) can be expressed as [14],

$$
T C F=\frac{1}{f_{r}} \frac{d f_{r}}{d T}
$$

From Fig. 5, we can find the dependence of resonance frequency on temperature is quasi-linear. Then we can compute the TCF of the device $\mathrm{B}$, device $\mathrm{C}$ and device $\mathrm{D}$ with linear fitting. Then the TCFs of device $\mathrm{B}$, device $\mathrm{C}$ and device $\mathrm{D}$ are $28 \mathrm{ppm} /{ }^{\circ} \mathrm{C}, 55 \mathrm{ppm} /{ }^{\circ} \mathrm{C}$ and $75 \mathrm{ppm} /{ }^{\circ} \mathrm{C}$, respectively. It can be seen that the device $\mathrm{D}$ is the most sensitivity to temperature and is more linear than that of device $\mathrm{B}$ and device $\mathrm{C}$. It can be concluded that the device $\mathrm{D}$ is the best temperature sensor among these SAW devices. The temperature sensitivity of device $\mathrm{D}$ is about $21 \mathrm{kHz} /{ }^{\circ} \mathrm{C}$, which means that the shift of resonance frequency is big enough to be detected easily by microwave instrument such as VNA.

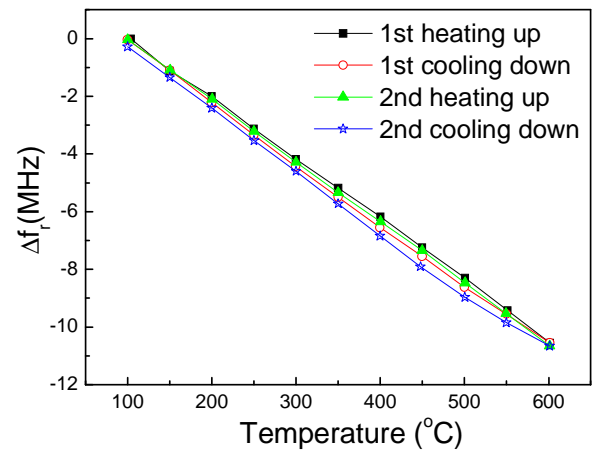

Fig. 5. Dependence of resonance frequency shift of device D on temperature. 
Fig. 6 shows dependence of resonance frequency shift of device D on temperature for two heating-up and cooling-down measurement cycles. It is observed that the device D is very stable below $600^{\circ} \mathrm{C}$ and has a good reproducibility for resonance frequencies working under different temperature. The stable temperature characteristic of the SAW device is because of the stable YCOB piezoelectric substrate, Au-Ti electrodes and the annealing procedure before measurements. Au-Ti thin film electrodes are widely used for high temperature sensors for their excellent oxidation resistance and outstanding electrical properties [12]. The annealing process have eliminated to voids in electrodes and released residual stresses in the substrates, thus improve the thermal stability of electrodes.

\section{Conclusions}

In this work, we have designed and fabricated SAW resonators with substrates of YCOB with cutting type of $\mathrm{X}-90^{\circ}$ and Z-90 and LGS with different Euler angle of $\left(0^{\circ}, 138.5^{\circ}, 117^{\circ}\right)$ and $\left(0^{\circ}, 138.5^{\circ}, 27^{\circ}\right)$. We studied the resonance frequency characteristics of these four different SAW devices under different temperatures. The results show that SAW devices with LGS and YCOB substrates have high temperature stability up to $600{ }^{\circ} \mathrm{C}$. The resonance frequency of SAW devices based on YCOB substrates decrease more linearly with temperature than that on LGS substrates. SAW device on YCOB substrates with cutting type of Z- $90^{\circ}$ have highest sensitivity to temperature of $21 \mathrm{kHz} /{ }^{\circ} \mathrm{C}$ and highest temperature coefficient of frequency (TCF) of $75 \mathrm{ppm} /{ }^{\circ} \mathrm{C}$, making it promising device for high temperature wireless sensors.

\section{Acknowledgements}

This work was financially supported by NSFC (No. 61223002).

\section{References}

[1] W.E. Bulst, G. Fischerauer, L. Reieidll: IEEE Transactions on Industrial Electronics, Vol. 48(2) (2001), p. 265.

[2] M.N. Hamidon, V. Skarda, N.M. White: IEEE transactions on Ultrasonics, Ferroelectrics, and Frequency control, Vol. 53(12) (2006), p. 2465.

[3] Kim, Kyungrim, et al: Sensors and Actuators A: Physical Vol. 178 (2012), p. 40.

[4] J.A. Thiele, M. Pereira da Cunha: IEEE transactions on Ultrasonics, Ferroelectrics and Frequency control, Vol. 52(4) (2005), p. 545.

[5] W. Shou-Qi, H. Jiro, U. Satoshi: Japanese Journal of Applied Physics, Vol. 42 (2003), p. 6124.

[6] P. Zheng, et al: in 2010 IEEE International Frequency Control Symposium, (2010), p. 297.

[7] J.A. Thiele, M. Pereira da Cunha: Sensors and Actuators B: Chemical, Vol. 113(2) (2006), p. 816.

[8] W.C. Wilson, M.D. Rogge, B.H. Fisher, et al: IEEE Sensors Journal, Vol. 12(6) (2012), p. 1993.

[9] L.C. Martin, J.D. Wrbanek, G.C. Fralick: in 19th International Congress on ICIASF 2001, (2001 ), p. 196.

[10] I. Shrena, D. Eisele, E. Mayer, L. M. Reindl, J. Bardong, M. Schmitt: in 3rd International Conference on IEEE 2009, (2009), p. 1

[11] T. NISHIDA, T. AMANO, T. SHIOSAKI, et al: in Ultrasonics Symposium, 2001 IEEE, Vol. 1 (2001), p. 179.

[12] J. Lee, C. Park, J.J Kim, et al: Journal of Physics D: Applied Physics, Vol. 33 (2000), p. 1953.

[13] M. B. Schulz, B. J. Matsinger, M. G. Holland: Journal of Applied Physics, Vol. 41 (1970), p. 2755.

[14] W.T Hsu, C.T.C Nguyen: in 5th IEEE International Conference on IEEE 2002, (2002), p. 731.

[15] G. Bu, D. Ciplys, M. Shur, et al: Electronic Letters, Vol. 39(9) (2003), p. 751. 